\title{
THE JOURNAL \\ of
}

\section{THE AUSTRALIAN MATHEMATICAL SOCIETY}

\section{VOLUME VIII - PART 2}

DAVID ELLIOTT

G. SZEKERES

LAJOS TAKÁCS

K. R. Pearson

K. R. Pearson

A. J. VAN Der Poorten

A. Shafaat

H. S. KONIJN and $\mathrm{R}$. SACKSTEDER

R. F. C. Walters

DAVID ELLIOTT

\section{MAY 1968}

M. L. Urquhart . . . . . . . . . . . . . 129

Kinematic geometry; an axiomatic system for Minkowski space-time . . . . . . . . 134

On dams of finite capacity . . . . . . . 161

Certain topological semirings in $R_{1}$. . . . 171

Embedding semirings with multiplicative unit 183

Transcendental entire functions mapping every algebraic number field into itself . . . . . . 192

On the number of topologies definable for a finite set. . . . . . . . . . . 194

Unbiased distinguishing of translation families and integrability with respect to a convolution of measures. . . . . . . . . . . . . . 199

Alternative derivation of some regular contimued fractions . . . . . . . . . . . . 205

Error analysis of an algorithm for summing certain finite series. . . . . . . . . .

\footnotetext{
Published for

THE AUSTRALIAN MATHEMATICAL SOCIETY by Wolters-Noordhoff NV - Groningen - The Netherlands
} 


\section{OFFICERS OF THE SOCIETY}

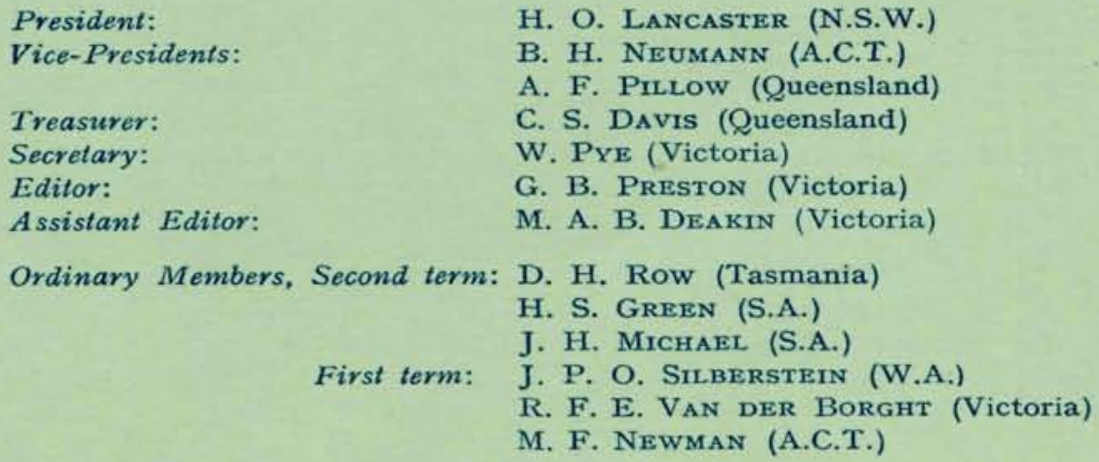

THE JOURNAL

Editor: G. B. Preston

Associate Editors:
R. F. E. Van der Borght,
Assistant Editor: M. A. B. Deakin E. Strzelecki,
G. A. Watterson

Selection of papers for publication is made by the Editor with the assistance of the Associate Editors. Manuscripts for publication should be sent either to the Editor or to one of the Associate Editors, at the address:

Journal of the Australian Mathematical Society.

Department of Mathematics,

Monash University.

Clayton, Victoria 3168, Australia.

Intending authors are asked to read the section "Preparation of Manuscripts" on the inside back cover of this issue.

Correspondence concerning papers after their acceptance for publication should be addressed to the Assistant Editor at the same address. Authors of papers printed in the Journal receive 50 off-prints of their papers free; additional off-prints may be ordered at cost. Excessive costs incurred by the Society through corrections or withdrawal of articles may be charged to the authors concerned.

All subscriptions and correspondence connected with accounts should be addressed to the Treasurer of the Society; and all other correspondence (such as orders for the Journal, and correspondence concerning exchanges), should be addressed to the Business Manager. The address in both cases is: The Australian Mathematical Society, Department of Mathematics, University of Queensland, St. Lucia, Queensland 4067, Australia.

Each volume of the Journal consists of four parts The price per volume is $\$ 15.00$ Australian.

\section{RECIPROCITY AGREEMENTS}

The Australian Mathematical Society has made Reciprocity Agreements with the American Mathematical Society, the Edinburgh Mathematical Society, the London Mathematical Society, the Deutsche Mathematiker Vereinigung and the Islenzka Staerdfraedafelagid using the agreement with the American Mathematical Society as a model. Under this agreement, members of these societies not normally resident in Australia may join the Australian Mathematical Society at half the current rates. Such members will not have the right to vote in the Society or have any other financial commitment. They will receive copies of the Journal free. 